CONGENITAL HEART DISEASE

\title{
Transcatheter closure of persistent ductus arteriosus with the Amplatzer duct occluder in very young symptomatic children
}

\author{
G Butera, G De Rosa, M Chessa, L Piazza, A Delogu, A Frigiola, M Carminati
}

Heart 2004;90:1467-1470. doi: 10.1136/hrt.2003.025122

See end of article for authors' affiliations

Correspondence to:

Dr Butera Gianfranco,

Paediatric Cardiology, Istituto Policlinico San

Donato, Via Morandi, 30,

20097 San Donato

Milanese, Milan, Italy;

gianfra.but@lycos.com

Accepted

17 February 2004

\begin{abstract}
Objectives: To analyse safety, efficacy, and follow up results of percutaneous closure of persistent ductus arteriosus (PDA) in very young symptomatic children.

Patients and design: Between March 2000 and March 2003, of 197 patients treated at the authors' institution 18 were symptomatic children aged $\leqslant 3$ years old. Seven of these children were $\leqslant 1$ year old. Indications for closure were failure to thrive (12 patients) and frequent respiratory infections (six patients). The procedure was carried out under heavy sedation with fluoroscopic control. The Amplatzer duct occluder device was used. Basal physical examinations and echocardiograms were performed before the procedure and at follow up (three, six, and 12 months and yearly thereafter).

Results: Mean (SD) age was $18.3(10)$ months and mean (SD) weight at closure was 9.1 (2.2) kg. Neither death nor any major complications occurred. Complications occurred in three patients aged $\leqslant 1$ year. Two patients had a mild inguinal haematoma. One patient had femoral artery thrombosis that was successfully treated by intravenous urokinase. The mean (SD) follow up was 12.8 (8.5) months. No problems occurred. Patients with recurrent respiratory infections had no significant recurrences and children who had failed to thrive had significantly increased growth.

Conclusions: In experienced hands, percutaneous closure of moderate to large PDA in very young symptomatic children is safe, effectively closes the PDA, and solves clinical problems.
\end{abstract}

T ranscatheter occlusion of persistent ductus arteriosus (PDA) with various occluders and coils is a well established alternative to surgical duct ligation. The degree of successful deployment is variable and the incidence of residual shunting is reported to be between $3 \%$ and $38 \% .^{1-9}$

A small to moderate sized duct can be readily closed with various devices. ${ }^{14-8}{ }^{10}$ Transcatheter closure of the larger ones is possible with a new device, the Amplatzer duct occluder (ADO)..$^{10-12}$

The use of the ADO is well established and reported in children and adults, but there are only occasional reports on symptomatic infants and very young children. ${ }^{10-12}$

In the present report we describe immediate and short term results with the use of the ADO to close moderate to large PDAs in a paediatric population of 18 symptomatic children, all aged $<3$ years

\section{PATIENTS AND METHODS}

From March 2000 to March 2003, 197 patients underwent transcatheter occlusion of a PDA. Eighteen of them were symptomatic young children and were treated with the ADO. Age at intervention ranged from 6 months to 3 years (median age 15 months). Median weight was $8 \mathrm{~kg}$ (range 4.5 to $16 \mathrm{~kg}$ ). Patients were assessed by echocardiography with a Vingmed System Five Performance (GE Vingmed Ultrasound, Horten, Norway) with a transducer appropriate to size and body weight.

\section{Inclusion criteria}

Patients who were selected for this device occlusion had clinical and echocardiographic features of a moderate to large PDA and weighed $>4500 \mathrm{~g}$. These patients had one or more of the following: symptoms and signs of cardiac failure, failure to thrive, frequent respiratory infections, bounding pulses, and cardiomegaly on chest radiography. Frequent respiratory infections were defined as more than six events a year. ${ }^{13}$ Failure to thrive was defined according to Hamil et al ${ }^{14}$

All patients had signs of significant left to right shunting through the PDA with left atrial enlargement and ventricular volume overload on two dimensional echocardiography.

\section{Device and procedures}

Informed consent was obtained from the parents of all patients.

The procedure was carried out under heavy sedation with fluoroscopy control. After percutaneous puncture of the femoral vein and artery, all haemodynamic variables were evaluated with pressure and saturation taken in all cardiac chambers. A descending aortogram in the lateral projection was recorded with a 4 French pigtail catheter to define the morphology and size of the duct. Subsequently, a 5 French multipurpose catheter was advanced from the venous side through the PDA into the descending aorta. A standard $150 \mathrm{~cm}$ (0.0035 inch) guidewire was used to exchange the multipurpose catheter for a 5 or 6 French delivery sheath that was advanced from the femoral vein into the descending aorta. An ADO 1 to $3 \mathrm{~mm}$ larger than the narrowest size of the duct was chosen.

The ADO (Aga Medical Corporation, Golden Valley, Minnesota, USA) is a cone shaped device, $7 \mathrm{~mm}$ in length, made of a 0.004 inch Nitinol wire mesh. A $2 \mathrm{~mm}$ retention skirt extends radially around the distal part of the device assuring secure fixation in the mouth of the PDA. Prostheses are available in sizes ranging from 6-4 to $14-12 \mathrm{~mm}$ at increments of $2 \mathrm{~mm}$. The larger measurement is at the aortic site and the smaller is at the pulmonary end. The device is attached by a recessed micro-screw to a 0.038 inch delivery cable made of stainless steel; it is delivered through a 5 to 6 French long sheath. For introduction into the delivery sheath the device is pulled into a special Teflon loader. The device is 
Table 1 Patients' data

\begin{tabular}{|c|c|c|c|c|c|c|c|c|c|c|c|c|c|c|c|}
\hline Patient & Sex & Indications & $\begin{array}{l}\text { Age } \\
\text { (months) }\end{array}$ & $\begin{array}{l}\text { Weight } \\
\text { (kg) }\end{array}$ & Centile & $\begin{array}{l}\text { Procedure } \\
\text { time (min) }\end{array}$ & $\begin{array}{l}\text { Fluoroscopy } \\
\text { time (min) }\end{array}$ & $\begin{array}{l}\text { SPAP } \\
(\mathrm{mmHg})\end{array}$ & $\begin{array}{l}\text { MPAP } \\
(\mathrm{mmHg})\end{array}$ & Qp:Qs & $\begin{array}{l}\text { PDA } \\
(\mathrm{mm})\end{array}$ & $\begin{array}{l}\text { PDA } \\
\text { device } \\
(\mathrm{mm})\end{array}$ & $\begin{array}{l}\text { FU } \\
\text { (months) }\end{array}$ & $\begin{array}{l}\text { Weight } \\
\text { at FU } \\
\text { (kg) }\end{array}$ & $\begin{array}{l}\text { Centile } \\
\text { at FU }\end{array}$ \\
\hline 1 & $\mathrm{~F}$ & FT & 9 & 7 & 6 & 70 & 8 & 26 & 15 & 2.2 & 3 & $8 \times 6$ & 36 & 14 & 50 \\
\hline 2 & $\mathrm{~F}$ & RRI & 25 & 12 & 50 & 80 & 9 & 25 & 14 & 1.9 & 3.5 & $6 \times 4$ & 36 & 18 & 50 \\
\hline 3 & $M$ & RRI & 35 & 15 & 75 & 85 & 12 & 40 & 30 & 1.7 & 4.5 & $8 \times 6$ & 36 & 23 & 75 \\
\hline 4 & $\mathrm{~F}$ & $\mathrm{FT}$ & 11 & 6.7 & $<3$ & 75 & 9 & 25 & 18 & 3.5 & 3.5 & $6 \times 4$ & 12 & 10 & 50 \\
\hline 5 & $\mathrm{~F}$ & FT & 10 & 5.6 & $<3$ & 65 & 7 & 55 & 41 & 2.8 & 4 & $6 \times 4$ & 12 & 9.5 & 50 \\
\hline 6 & $M$ & RRI & 24 & 11 & 25 & 75 & 8 & 35 & 24 & 2.3 & 3 & $6 \times 4$ & 36 & 14.5 & 50 \\
\hline 7 & $\mathrm{~F}$ & RRI & 36 & 16 & 75 & 80 & 10 & 20 & 14 & 1.9 & 4 & $6 \times 4$ & 12 & 17 & 75 \\
\hline 8 & $M$ & $\mathrm{FT}$ & 24 & 10 & 6 & 85 & 12 & 23 & 13 & 3.6 & 4 & $6 \times 4$ & 24 & 15 & 25 \\
\hline 9 & $\mathrm{~F}$ & $\mathrm{FT}$ & 6.5 & 4.5 & $<3$ & 70 & 8 & 50 & 32 & 3.4 & 6 & $10 \times 8$ & 24 & 12 & 25 \\
\hline 10 & $M$ & FT & 8 & 6.8 & $<3$ & 70 & 10 & 50 & 35 & 1.8 & 5 & $8 \times 6$ & 21 & 13 & 30 \\
\hline 11 & $\mathrm{~F}$ & RRI & 14.5 & 11 & 50 & 90 & 14 & 28 & 14 & 2.0 & 3.2 & $6 \times 4$ & 12 & 13 & 50 \\
\hline 12 & $\mathrm{~F}$ & RRI & 26 & 12 & 25 & 75 & 8 & 32 & 18 & 2.2 & 4 & $8 \times 6$ & 12 & 14 & 25 \\
\hline 13 & $\mathrm{~F}$ & $\mathrm{FT}$ & 6 & 6 & 3 & 100 & 10 & 30 & 16 & 2.1 & 3 & $6 \times 4$ & 6 & 9 & 10 \\
\hline 14 & $\mathrm{~F}$ & $\mathrm{FT}$ & 18 & 8 & $<3$ & 80 & 8 & 23 & 18 & 2 & 3.5 & $6 \times 4$ & 3 & 10 & 3 \\
\hline 15 & $M$ & $\mathrm{FT}$ & 29 & 10.5 & $<3$ & 85 & 13 & 30 & 20 & 2.1 & 4 & $8 \times 6$ & 3 & 11.5 & 3 \\
\hline 16 & $\mathrm{~F}$ & $\mathrm{FT}$ & 15 & 7 & $<3$ & 80 & 9 & 30 & 16 & 2 & 2.5 & $6 \times 4$ & 3 & 9 & 3 \\
\hline 17 & $\mathrm{~F}$ & $\mathrm{FT}$ & 9 & 6.5 & $<3$ & 75 & 8 & 35 & 18 & 2.5 & 2.8 & $5 \times 4$ & 3 & 8.5 & 5 \\
\hline 18 & $\mathrm{~F}$ & $\mathrm{FT}$ & 20 & 10 & 3 & 85 & 10 & 25 & 16 & 2.5 & 2.8 & $5 \times 4$ & 3 & 11.5 & 25 \\
\hline
\end{tabular}

F, female; FT, failure to thrive; M, male; MPAP, mean pulmonary artery pressure; Qp:Qs, pulmonary to systemic flow ratio; PDA, persistent ductus arteriosus; RRI, recurrent respiratory infections; SPAP, systolic pulmonary artery pressure.

introduced into the delivery sheath and advanced, under fluoroscopic guidance, into the descending aorta, where the retention disk is deployed. Then, the sheath and the delivery cable are pulled back until the retention disc is against the aortic end of the ampulla. While a gentle tension is maintained on the delivery cable, the introducing sheath is withdrawn into the pulmonary artery to deploy the conical part of the ADO. With the device still attached to the cable, a descending aortogram is recorded in the lateral projection to confirm the device's position. Once proper device position is confirmed, the device is released by anticlockwise rotation of the delivery cable. A repeat descending aortogram is recorded 10 minutes after the release to check for residual shunts. Before the procedure was ended, pullback pressure measurements were obtained in the aortic arch and in the pulmonary arteries to check for stenosis in these vessels. Prophylactic antibiotics with cephalosporin were administered during the procedure. All patients were discharged 24 hours after the procedure and given no medication.

\section{Follow up}

All patients underwent clinical investigation, chest radiography, urine stick test to check for haematuria, and transthoracic echocardiography before discharge and at two months. Thereafter, patients underwent echocardiography at $3,6,12$, and 24 months after the procedure. Special attention was paid to residual ductal flow and left pulmonary artery or aortic arch stenosis. ${ }^{15}{ }^{16}$ A Doppler flow velocity $\geqslant 1.5 \mathrm{~m} / \mathrm{s}$ measured at the origin of the left pulmonary artery or at the aortic arch was considered to be a significant sign of stenosis.

Endocarditis prophylaxis was discontinued at the six months' follow up if the duct was completely closed.

\section{Statistical analysis}

Results are expressed as mean (SD) or median (range).

Body weight and centiles of body weight at the procedure and at follow up were compared by the paired $t$ test and the Wilcoxon test, respectively. A $p<0.05$ was considered significant. All tests were two sided.

\section{RESULTS}

\section{General characteristics}

During the study all patients meeting the inclusion criteria were treated percutaneously and none was underwent surgery. Table 1 reports the patients' data. Mean (SD) age was 18.3 (10) months and mean (SD) weight at the time of the procedure was 9.1 (2.2) $\mathrm{kg}$. Clinical indications for closure were failure to thrive in 12 patients and frequent respiratory infections in six. Among the patients who were studied, seven were $<1$ year old. All these patients had failed to thrive with severely reduced weight (median centile $<3$ ). The mean (SD) PDA diameter at its narrowest point was 3.7 (0.9) $\mathrm{mm}$. The mean (SD) pulmonary to systemic flow ratio was $2.3(0.6)$

\section{Procedure, technical problems, and complications}

Delivery of the device was successful in all patients. Figures 1 and 2 show the closure of a PDA in one patient. Mean (SD) fluoroscopy and procedure times were 9.6 (2) minutes and 79 (8.4) minutes, respectively. No death occurred.

All complications occurred in subjects aged $\leqslant 1$ year. Mild inguinal haematoma occurred in two patients (patient 5, age 10 months, and patient 10 , age 8 months). In patient 9 (age 6.5 months), closure with an ADO $6 \times 4 \mathrm{~mm}$ was unsuccessful; therefore, an ADO $10 \times 8 \mathrm{~mm}$ was chosen with success and no stenosis on either the aortic or the pulmonary side occurred.

In patient 17 (9 months old), thrombosis of the right femoral artery occurred. Heparin (continuous intravenous

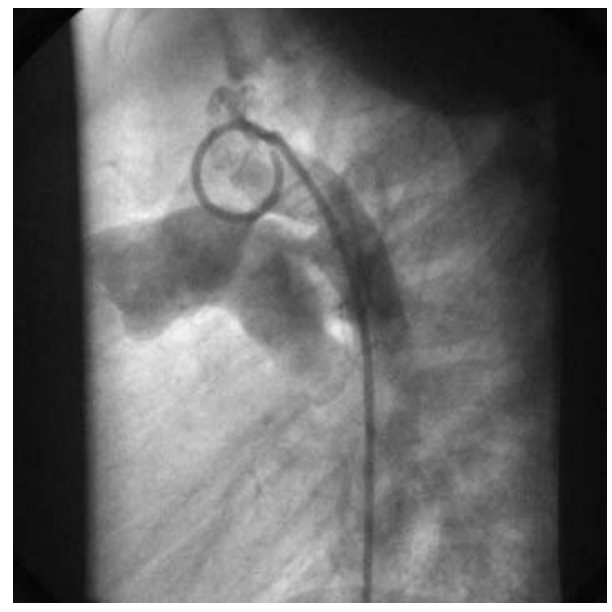

Figure 1 Still frame cine image in the lateral projection in the descending aorta of a child with a $3.5 \mathrm{~mm}$ PDA. 


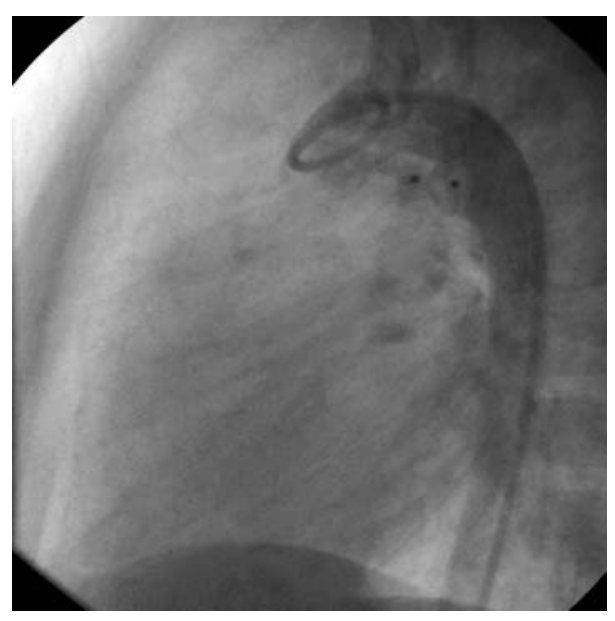

Figure 2 Still frame cine image in the lateral projection in the descending aorta showing the device in the proper position. There is a trivial residual shunt through the device.

infusion of $20 \mathrm{U} / \mathrm{kg} / \mathrm{h}$ ) was used unsuccessfully. Urokinase intravenous infusion (loading dose $4000 \mathrm{U} / \mathrm{kg}$ over 10 minutes followed by $4000 \mathrm{U} / \mathrm{kg}$ for six hours) produced a successful and complete turn of the pulse with no sequelae.

Finally a technical problem occurred in a 25 months patient (patient 15). In this patient, an ADO $6 \times 4 \mathrm{~mm}$ was too small to close the defect, therefore an ADO $8 \times 6$ was successfully used.

In eight patients there was a trivial intraprosthetic residual shunt immediately after the procedure.

In four patients aged $<1$ year (patients $1,9,10$, and 18) the device encroached partially on the origin of the left pulmonary artery; however, pullback pressure measurements showed no gradient, pulmonary artery angiography showed no preferential blood flow, and no significant acceleration was measured on Doppler echocardiography.

At 24 hours, colour Doppler flow mapping showed complete closure with no evidence of obstruction of the left pulmonary artery or the descending aorta.

\section{Follow up}

All patients were discharged home the day after the procedure and were followed up for an average (SD)of 12.8 (8.5) months. Neither major nor minor complications occurred. The absence of obstruction on the pulmonary side and on the aortic side was confirmed during the follow up.

Patients with partial device protrusion on the origin of the left pulmonary artery had no significant Doppler gradient.

Patients with recurrent respiratory infections had no significant recurrences. Patients who had failed to thrive had significantly increased weight $(\mathrm{p}<0.001)$ and centiles of body weight (from a median of $<3$ to a median of 25 , $\mathrm{p}<0.001 ;$ table 1$)$.

\section{DISCUSSION}

Since the first percutaneous closure of a PDA performed by Porstmann ${ }^{17}$ various devices and coils ${ }^{1-9} 18$ have been introduced in clinical practice. The major drawbacks of these devices and coils are the high incidence of residual shunt, the sometimes complex delivery system, and large delivery sheaths and their unsuitability for large PDAs or small children. ${ }^{1-9}{ }^{18}$ Masura et $a l^{10}$ reported the successful use of a new self expandable Nitinol device (ADO) to occlude moderate to large PDAs.

Faella and Hijazi ${ }^{11}$ reported the immediate and short term results of the international registry of transcatheter closure with ADO. Three hundred and sixty patients were treated at a median age of 2.1 years. The occlusion rate was up to $100 \%$ at one year's follow up. Seven patients (2\%) experienced significant complications: death (one patient), haemolysis (one patient), transient asystole (one patient), surgery due to device embolisation (one patient), device misplacement (one patient), ST depression (one patient), and blood transfusion due to significant blood loss during procedure (one patient).

Bilkis et al ${ }^{12}$ reported on a large series of 205 patients with a PDA occluded by the ADO. The patients were aged between 2 months and 50 years (median 1.9 years) and the PDA measured from 1.8 to $12.5 \mathrm{~mm}$ (median $4.9 \mathrm{~mm}$ ) at its narrowest point. Closure was successful in all patients. Complications occurred in six patients $(3 \%)$ : three experienced embolisation of the device that required surgery, an infant of $5 \mathrm{~kg}$ acquired mild aortic narrowing after deployment of a large device $(10 \times 8 \mathrm{~mm})$, and, lastly, two patients required blood transfusion due to significant blood loss.

However, in these studies infants were part of a case series along with adults. Furthermore, no data are reported about symptomatic infants and their follow up. Therefore, there are no reports specifically concerning young symptomatic infants with moderate to large PDA.

In our series of 18 symptomatic children aged $<3$ years closure was successful in all. Only one severe complication occurred in a child aged $<1$ year (thrombosis of the femoral artery) that was successfully treated by urokinase. Furthermore, two minor complications (mild inguinal haematoma) occurred, also in patients aged $\leqslant 1$ year. Therefore, in our experience, in this group of patients percutaneous PDA closure is a procedure with moderately higher risk than in older patients.

No late major complications occurred. Furthermore, during the follow up, patients with frequent respiratory infections had no significant recurrences and patients who had failed to thrive had significantly increased growth. Lastly, no patient developed stenosis in either the left pulmonary artery or the aortic arch. In particular, this was true in patients aged $\leqslant 1$ year, who may be at risk for such complication because of reduced vessel size.

\section{Limitations of the study}

Although in our series of 18 young children, percutaneous techniques of ductus arteriosus closure appear to be safe, major complications may occur as reported in the literature. ${ }^{10-12}$

A potential problem is related to the fact that the PDA is a remnant of the sixth aortic arch and it therefore forms a $30^{\circ}$ angle with the aorta. The retention disk of the ADO has a right angle; thus, the potential for aortic distortion or obstruction may exist in babies. This problem did not occur in our experience; however, a device with a modified retention disk is under clinical investigation, which may eliminate this drawback of the current device. ${ }^{19}$

Finally, further clinical evaluations and longer follow up are needed to assess any potential limitation related to the use of this device in very young children.

\section{Conclusions}

In conclusion, in experienced hands, percutaneous closure of moderate to large PDA in young symptomatic children is safe and effective in closing the PDA and in solving clinical problems.

\section{Authors' affiliations \\ G Butera, G De Rosa, M Chessa, L Piazza, A Delogu, A Frigiola,}

M Carminati, Paediatric Cardiology, Istituto Policlinico San Donato, San Donato Milanese, Milan, Italy 


\section{REFERENCES}

1 Rashkind WJ, Mullins CE, Hellenbrand WE, et al. Nonsurgical closure of patent ductus arteriosus: clinical application of thee Rashkind PDA occluder. Circulation 1987;75:583-92.

2 Hosking MCK, Benson LN, Musewe N, et al. Transcatheter occlusion of the persistently patent ductus arteriosus: forty-month follow-up and prevalence of residual shunting. Circulation 1991:84:2313-7.

3 Latson LA, Hofschire PJ, Kugler JD, et al. Transcatheter closure of patent ductus arteriosus in pediatric patients. J Pediatr 1989;115:549-53.

4 Rao PS, Sideris EB, Haddad J, et al. Transcatheter occlusion of patent ductus arteriosus with adjustable buttoned device: initial clinical experience. Circulation 1993:88:1119-26.

5 Verin VE, Saveliev VS, Kolody SM, et al. Results of transcatheter closure of patent ductus arteriosus with the Botallooccluder. J Am Coll Cardiol 1993;22:1509-14.

6 Moore JW, George L, Kirkpatrick SE, et al. Percutaneous closure of the small ductus arteriosus using occluding spring coils. J Am Coll Cardiol 1994; $23: 759-65$

7 Lloyd TR, Fedderly R, Mendelsohn AM, et al. Transcatheter occlusion of patent ductus arteriosus with Gianturco coils. Circulation 1993;88:1412-20.

8 Hijazi ZM, Gegge RL. Results of anterograde transcatheter closure of patent ductus arteriosus using single or multiple Gianturco coils. Am J Cardiol 1994;74:925-9.

9 Hijazi ZM, Lloyd TR, Beekman RH III, et al. Transcatheter closure with single or multiple Gianturco coils of patent ductus arteriosus in infants weighing $>8 \mathrm{~kg}$ : retrograde versus anterograde approach. Am Heart J 1996;132:827-35.
10 Masura J, Walsh K, Thanopoulous B, et al. Catheter closure of moderateto large-sized patent ductus arteriosus using the new Amplatzer duc occluder: immediate and short-term results. J Am Coll Cardiol 1998;31:878-82

11 Faella HJ, Hijazi ZM. Closure of the patent ductus arteriosus with the Amplatzer PDA device: immediate results of the international clinical trial. Cathet Cardiovasc Intervent 2000;51:50-4.

12 Bilkis AZ, Alwi M, Hasri S, et al. The Amplatzer duct occluder: experience in 209 patients. J Am Coll Cardiol 2001;37:258-61.

13 Burgio GR. II bambino con infezioni ricorrenti. In: Plebani A, ed. Immunologia pediatrica. Milan: McGraw Hill Libri Italia Milano, 1998:17.

14 Hamil PV, Drizd TA, Johnson CL, et al. Physical growth: national center for health statistics percentiles. Am J Clin Nutr 1979:32:607-29.

15 Musewe NN, Benson LN, Smallhorn JF, et al. Two dimensional echocardiography and color flow Doppler evaluation of ductal occlusion with the Rashkind prostheses. Circulation 1989;80:1706-10.

16 Smallhorn JF, Hutha JC, Anderson RH, et al. Suprasternal cross-sectional echocardiography in assessment of patent ductus arteriosus. Br Heart $J$ 1982;48:321-30

17 Porstmann W, Wierny L, Warnke H. Closure of the persistent ductus arteriosus without thoracotomy. Ger Med Mon 1967;12:259-61.

18 Celiker A, Qureshi SA, Bilgic A, et al. Transcatheter closure of patent arterial duct using controlled-release coils. Eur Heart J 1997; 18:450-4.

19 Masura J, Gavora P, Podnar T. Transcatheter occlusion of patent ductus arteriosus using a new angled Amplatzer duct occluder: initial clinical experience. Catheter Cardiovasc Interv 2003;58:261-7.

\section{IMAGES IN CARDIOLOGY}

Severe aortic insufficiency in a patient with sinus of Valsalva aneurysm invading the interventricular septum

\begin{abstract}
27 year old man presented with a history of dyspnoea on exertion that progressed to dyspnoea at rest. ECG showed left bundle branch block and first degree atrioventricular block. Physical examination revealed a holodiastolic rumble at the left sternal border. A transthoracic echocardiogram showed an enlarged left ventricle with severe aortic regurgitation. A cystic lesion in the base of the septum, communicating with the left ventricular outflow tract, was noted. The patient underwent aortic valve replacement. Intraoperative transoesophageal echocardiography and findings at surgery were consistent with a sinus of Valsalva aneurysm, destroying the aortic valve and dissecting into the interventricular septum. The patient is doing well on follow up three years later.

Sinus of Valsalva aneurysms are rare, occurring in $0.14-0.96 \%$ of patients undergoing open heart surgery. Aneurysms dissecting into the interventricular septum are even less frequent, with only about 50 cases described in the English literature. Complications include infective endocarditis, atrioventricular conduction abnormalities, and aortic regurgitation with varying degrees of severity, most likely due to lack of anatomical support of the aortic leaflet. This report demonstrates the transthoracic and transoesophageal echocardiographic two dimensional and colour Doppler findings of a sinus of Valsalva aneurysm with dissection into the interventricular septum and severe aortic regurgitation, illustrating the loss of anatomical support of the leaflet causing valvar incompetence.
\end{abstract}

G V Moukarbel

A B Abchee aa14@aub.edu.lb

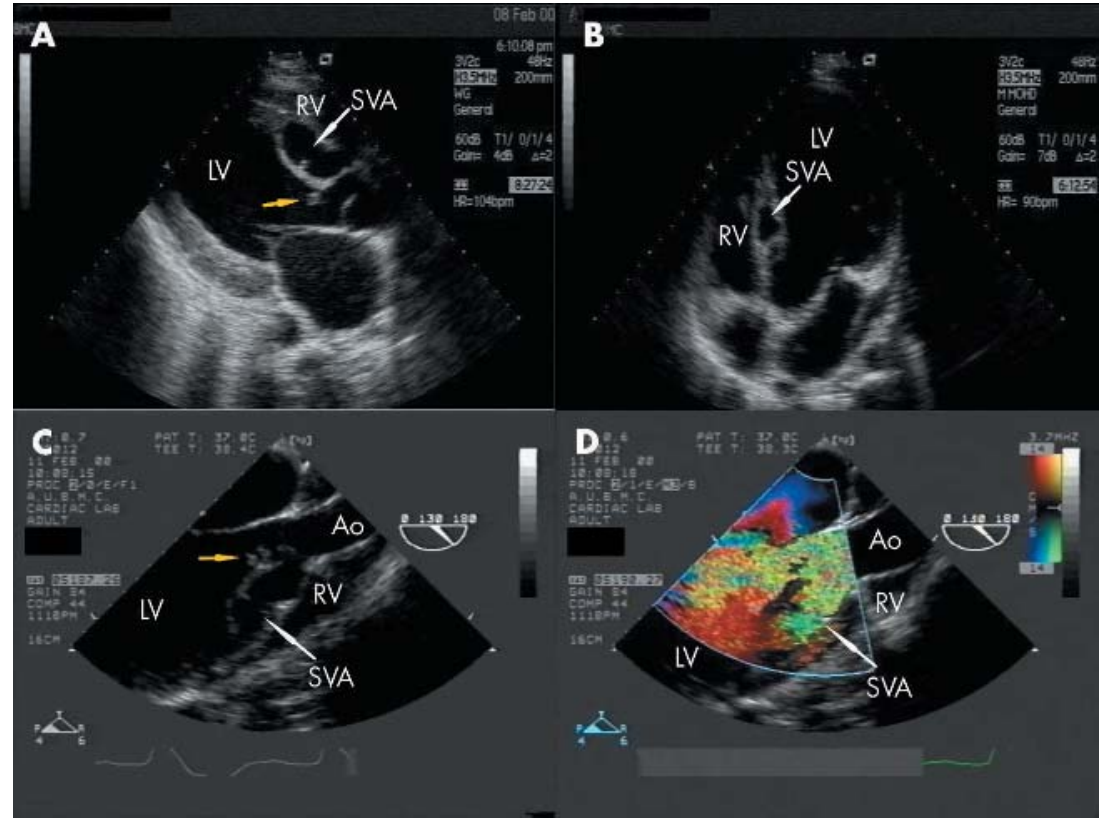

Transthoracic parasternal (A) and apical (B) views showing the aneurysm eroding into the basal septum. Transoesophageal long axis view without (C) and with (D) colour Doppler imaging showing severe aortic regurgitation with the regurgitant flow filling the aneurysm. Yellow arrows in (A) and (C) point to the disrupted aortic leaflet. Ao, aorta; LV, left ventricle; RV, right ventricle; SVA, sinus of Valsalva aneurysm. 